\title{
LA IMAGEN DE AMÉRICA LATINA EN LAS LETRAS HÚNGARAS Y LA PRESENCIA DE LA LITERATURA HÚNGARA EN AMÉRICA LATINA UN ESBOZO
}

\author{
Éva TóTH
}

Pen Club, Hungría

\section{The Image of Latin America in Hungarian Literature and the Presence of Hungarian Literature in Latin America}

The author, who is a poet, editor, and literary translator is one of those who bave done a lot to make Latin American literature known in Hungary, and Hungarian literature known in Latin Ameria. The study gives a brief overvien of some of the most important characteristics of this so-far little researched topic as well as provides some examples of the main representatives.

Voy a tratar dos tópicos aparentemente divergentes o, por lo menos no del todo simétricos. El primero es la imagen de América Latina en las letras húngaras y el segundo la presencia de la literatura húngara en América Latina. Por supuesto, voy a transgredir los límites establecidos por mí misma, no obstante no podré agotar el tema ni mucho menos.

Por razones obvias, los contactos entre Hungría y el mundo hispano no han sido ni estrechos ni abundantes. Hungria figura en el Romancero español (y catalán) como sinónimo de un imperio lejano y fabuloso y lo mismo ocurre en una decena de dramas de Lope de Vega con asunto húngaro. A pesar de que España y parte de Hungría pertenecían en aquella época al mismo imperio, el Habsburgo, la Hungría de Lope poco tiene que ver con la realidad histórica. Garcilaso de la Vega es probablemente el primer poeta español en elogiar el "Danubio, río divino", pero a los habitantes del escenario de su exilio no les presta más atención que Ovidio a los bárbaros de Tomi. La revolución y guerra de independencia de 1848/1849, aplastadas por los Habsburgo, atrajeron la atención del mundo hacia Hungría. En la Nación, periódico bonaerense, en una de sus Cartas de Nueva York José Martí escribe lo siguiente:

„Iremos hoy adonde va Nueva York, a ver el Cristo del pintor húngaro Munkácsy. ¡Éljen, éljen! - que quiere decir ¡viva! ¡viva! - gritan pintores, poetas, periodistas, clérigos, políticos, dondequiera aparece Munkácsy, que está ahora de visita en Nueva York... (28 de enero de 1887)". Martí califica Hungría "el bello país de selvas y viñedos" y la gente del país, dice, "en música, son Liszt; en poesía, Petõfi; Kossuth en oratoria...". No es pues de extrañar que sea en Cuba donde se tradujera por primera vez al castellano parte de la obra poética de Petőfi. Hoy podemos ya afirmar que los nombres de Petőfi, Ady y Attila József no son desconocidos para el lector de habla hispana. 
Las literaturas hispánicas presentan ciertas semejanzas con la húngara en cuanto al entorno histórico-social, la entonación, la pintura de los caracteres y los objetivos. Los escritores del noventa y ocho nos recuerdan a los agrupados alrededor de la revista Nyugat (Occidente), las imágenes resplandecientes de García Lorca al surrealismo popular de László Nagy e incluso se puede trazar un paralelo entre el indigenismo, lo que es más, hasta el realismo mágico y el populismo en la literatura húngara de los años treinta.

$\mathrm{Y}$ ahora empecemos a presentar algunas referencias de América del Sur en nuestras letras.

En su Crónica sobre los acontecimientos destacados del mundo publicada en Cracovia en 1559, István Székely ya narra el descubrimiento del Nuevo Mundo y la palabra América la utiliza por primera vez el erudito calvinista Albert Szenczi Molnár en 1592. Antes de esta fecha, en 1589, Bálint Balassi, el gran poeta renacentista quien en el prólogo de su Hermosa comedia búngara menciona a Cortés como notable versificador, declara en una carta su intención de alistarse como soldado español a sueldo e irse allende el mar para no volver jamás a su país. Medio siglo después, movido por la misma amargura a causa de la desesperada situación de la patria amenazada por el imperio otomán, otra gran figura de la literatura húngara, Miklós Zrínyi escribe en su Remedio contra la ponzoña turia que si no somos capaces de defender nuestro país, "hay tierra en abundancia en el Brasil, vayamos a pedir que nos concediera una provincia el rey de España, hagámonos ciudadanos allá".

La primera mención de índole puramente estética de una poesía o la poesía latinoamericana así como la traducción al húngaro de un poema de América del Sur se debe al autor de nuestro Himno nacional, Ferenc Kölcsey. En su tratado Sobre la poesía, escrito en 1808, cita un fragmento del poema de Inca Garcilaso de la Vega paralelamente con su traducción del mismo para demostrar su tesis según la cual no es la métrica ni la rima que hacen la poesía.

Dejando a parte las referencias esporádicas a América del Sur en textos poéticos como las Cordilleras en el poema de Dániel Berzsenyi (1776-1836) $A$ los húngaros, Perú en un fragmento de Mihály Vörösmarty (1800-1855), Cortez Nándor es decir Hernán Cortés en el Credo de János Vajda (1827-1897), América y Colón en Árpád Tóth (18861928), Colón en varios poemas de Miklós Radnóti (1909-1944) etc., vamos a demostrar a grandes rasgos el efecto que el Libertador ejerció sobre uno de los políticos más importantes de la historia de Hungría.

La figura señera de la época de las reformas en Hungría - entre 1825 y 1848 - el conde István Széchenyi, aunque no ha actuado en el terreno de las bellas letras pero sí fue un excelente y eficaz publicista. Sus libros Crédito, Lumbre y Estadio tuvieron una gran repercusión en su país y sus diatribas contra la casa de los Habsburgo escritas en alemán fueron leídas en toda Europa. El joven aristócrata a quien su adversario político, Lajos Kossuth calificó "el más grande de los húngaros", el creador de la Academia de Ciencias, del primer puente permanente sobre el Danubio, del Casino Nacional, se siente apasionadamente atraído por el Nuevo Mundo y entre sus ideales se halla Bolívar. El 9 de mayo de 1819 escribe en su diario secreto lo siguiente: "Los imperios de antaño fueron Egipto, Grecia, Roma - pero el imperio a venir para nosotros es América". El 21 de julio 
escribe de manera imprevista "... iré a morir a Colombia". Más tarde escribe: "En mi época los transformadores del mundo son: Bonaparte, Washington, Pitt, Byron, Goethe, Bolívar." En otro sitio comenta: "Las naciones, si nos permitimos compararlas con las personas, tienen cuatro edades. Durante la infancia y la juventud se desarrollan las cualidades más hermosas y más nobles -como nos lo recuerda la historia del Imperio Romano y de Grecia- así como en América Washington, Franklin, Bolívar, Itúrbide, San Martín testimonian la verdad de mi tesis."

Entre las dos guerras mundiales surge dentro del vanguardismo internacional un caso singular, el de Zsigmond Remenyik. Nacido en 1900 de una familia de hacendados, inspirado en la revista vanguardista de Lajos Kassák, emigró a América del Sur y pasó allí seis años vagando por Argentina, Paraguay, Bolivia, Chile y Perú, trabajando y pasando hambre. Alli llega a la madurez y a su vocación de escritor: estar siempre al lado de los despojados. En Valparaíso se integra a un grupo vanguardista compuesto de jóvenes escritores, pintores y músicos encabezado por el poeta anarquista Neftalí Agrella quien será una importante figura en la narrativa de Remenyik así como su esposa india (más bien mestiza) Águida, tempranamente muerta. György (Georges) Ferdinandy, él mismo un escritor húngaro-latinoamericano, califica la obra de Remenyik -incluso la (mayor) parte escrita en húngaro y ya en Hungría- como „hispanoaméricaine” en su monografia publicada en francés por la prestigiosa editorial Mouton. La hoja vanguardista Rosa náutica que lleva una xilografia de Sándor Bortnyik en el dorso y entre cuyos patrocinadores figuran Vicente Huidobro y Jorge Luis Borges, entre otros, aparece en Valparaíso en 1922 así como su "epopeya" La tentación de los asesinos y el año siguiente se publica en Lima Las tres tragedias del lamparero alucinado. De su novela corta, Los juicios del dios Agrella él mismo tradujo al húngaro una variante abreviada y la publicó en la revista Szép Szó en 1938. La obra de Remenyik escrita en español y traducida al húngaro se ve publicada tan sólo en 1979; quince años después de su muerte, pero varias de sus novelas escritas ya en Hungría continúan elaborando sus experiencias adquiridas en América del Sur. Aquí cabe mencionar, a título de lo curioso, que, según nuestro suponer, se debe al contacto con Remenyik que Attila József utilizara la palabra guano en uno de sus grandes poemas, $A l$ borde de la ciudad, escrito en 1933:

Al borde de la ciudad, en donde vivo,

vuela el hollin en blandas alas

como murciélagos pequeños

y se solidifica como el guano...

(Versión de Fayad Jamís)

La novela de László Passuth escrita en 1939, El Dios de la lluvia llora sobre México tuvo mucho éxito en Hungría al igual que las demás novelas históricas de este culto y prolífico autor. Además de ser publicada en media docena de idiomas, tuvo hasta una edición pirata en español como el mismo autor lo declaró con no poco orgullo. 
György Ferdinandy a quien ya hemos mencionado en su calidad de monógrafo de Zsigmond Remenyik, vive desde hace varias décadas en Puerto Rico y, siempre en húngaro, describe su entorno "ancho y ajeno" con simpatía.

Aunque ya en el diario de Francisco de Miranda hay referencias a su "Viaje a Ungria" en 1785 donde menciona "al famoso Haydn" quien trabaja al servicio del duque Esterházy, y en 1904 Rubén Darío hiciera una crónica del entierro de Mór Jókai, el gran novelista, la veta de motivos húngaros se ensancha sólo después de la segunda guerra mundial, con la visita a Hungía de escritores comṕrometidos como Pablo Neruda, Nicolás Guillén, Miguel Ángel Asturias. Neruda, gran viajero del mundo y sobre todo del mundo llamado socialista, menciona Hungría con frecuencia y hasta publica un tomo de poemas con el título La miel de Hungria y junto con Asturias escribe en 1965 un libro entre poesía y prosa en loor a la cocina húngara, llamado Comiendo en Hungria el cual ha tenido varias ediciones en ocho idiomas. $\mathrm{Y}$ aquí les comunico un verdadero hallazgo filológico que di a conocer en mi ponencia Neruda en Hungría, Hungria en Neruda dictada en la Universidad de Oxford en 1989. Durante una de sus estancias en Hungría, en una entrevista, Neruda declaró: "El próximo año voy a traducir los poemas más bellos de Petőfi, Ady y Attila József.". El plan no se realizó pero quedaron sus huellas en el tomo póstumo El fin de viaje, publicado en 1982. En las páginas de 17 a 20 , pueden leerse, señalados con númetos romanos, aunque en orden erróneo, fragmentos de la Oda de Attila József. Según la nota a pie de la página, el manuscrito fue conservado por Matilde, esposa de Neruda. Por supuesto no se trata de plagio ni mucho menos de un plagio póstumo. Probablemente Neruda escribió a mano la traducción oral al francés de su traductor húngaro György Somlyó y después de su muerte le atribuyeron la autoría del fragmento. Así, pues, podemos considerar a Neruda también como traductor de Attila József, además del cubano Fayad Jamís, el argentino Hugo Acevedo y otros. Attila József aparece en poemas de Juan Gelman, de Jorge Alejandro Boccanera, de Luis Rogelio Nogueras y Yolanda Ulloa.

Las restricciones ideológicas, como lo hemos experimentado en Hungria, tienen a veces subproductos inesperados. En los años cincuenta surgió una cantidad de excelentes traducciones y libros -de poesía y de prosa- para niños hechos por escritores cuyas obras originales no llegaron a publicarse por causa de la política cultural estalinista en vigor. Algo similar sucedió con La tragedia del hombre, drama magistral de Imre Madách escrito en 1860 y traducido a más de veinte idiomas. El excelente escritor cubano Virgilio Piñera (1912-1979) quien, después de haber ganado el Premio Casa de las Américas, cayó en desgracia, no publicaron sus obras originales sino que se vio obligado a trabajar de traductor en el Instituto Cubano del Libro cumpliendo con una norma diaria de seis páginas o en el caso de un texto dificil, de cuatro. Así es como tradujo del francés La tragedia del hombre y yo tuve el honor de trabajar con él en la versión definitiva y logré convencerle -sin mucha insistencia además- de escribir un esayo sobre Madách lo que se publicó primero en húngaro.

La literatura húngara hizo su entrada en la literatura mundial con Petôfí a pesar de poseer un cuerpo considerable ya en la Edad Media y haber participado, aunque con cierto atraso, en todas las corrientes literarias y artísticas europeas. En cuanto a América 
Latina, después del surgimiento de algunas figuras importantes durante el periodo colonial y a pesar de la importancia de Darío y el indigenismo llegó a la mayoría de edad y al mismo tiempo a una difusión y reconocimiento a escala mundial con el boom o sea con el realismo mágico que se hace valer retroactivamente englobando escritores tan diversos entre sí como Asturias y Borges.

Podemos decir que las obras importantes, hasta algunas menos importantes de la literatura latinoamericana se publicaron en buenas y a veces excelentes traducciones y en grandes tirajes en Hungria, y que forman parte de la visión literaria del lector culto húngaro y se ven analizados en libros enteros por especialistas húngaros como es el caso de Katalin Kulin sobre García Márquez, Zsuzsa Haraszti sobre Mario Vargas Llosa o Zsuzsanna Csikós sobre Carlos Fuentes y existe una Breve bistoria de la literatura bispanoamericana, obra de László Scholcz (2005). Mientras que nosotros podemos jactarnos de toda una hueste de expertos húngaros que se dedican a transmitir lo latinoamericano, no existe ningún especialista de la literatura o más ampliamente, de la lengua, de la historia, de la cultura húngaras en América Latina. Aquí cabe mencionar no obstante un libro del cubano Salvador Bueno, Cinco siglos de relaciones entre Hungria y América Latina, útil compilación publicada en 1977 por la Editorial Corvina de Budapest. Y ahora llegamos a una observación que atañe a la sociología de la literatura o la historia de las ideologías. Desde un interés geográfico-histórico en los comienzos, América Latina entró en el foco de los húngaros con la Independencia, anhelada por ellos también, de nuevo con la revolución cubana, con la solidarización con el Tercer Mundo, fomentada oficialmente y canalizada por la fundación de la cátedra de español de la Universidad Eötvös Loránd de Budapest en 1957 y la de Szeged diez años más tarde.

Otra consideración importante que puede derivarse de lo dicho es que a los autores latinoamericanos se les traduce al húngaro casi siempre del original o, en el caso de la poesía, a base de traducciones literales hechas por filólogos y con la colaboración de poetas establecidos. En cuanto a la presencia de la literatura húngara, se debe a ediciones hechas en España, a distintas formas de coedición de editoriales húngaras y cubanas como es el caso de mi Antología de la poesía húngara la segunda edición de la cual se publicó en diez mil ejemplares y figurando durante una semana entre los diez libros más vendidos en Cuba. Así que detrás de una publicación de algo húngaro hay casi siempre un húngaro que la promueve como que era el caso de Paulo Rónai en el Brasil $o$ las traducciones se hacen de un tercer idioma.

Por supuesto no estamos solicitando aquí una reciprocidad cuantitativa en cuanto a traducciones o publicaciones; y no porque América Latina es todo un continente que consta de varios países y nosotros somos una nación de apenas quince millones de húngarohablantes. Lo que se traduce y así se conoce de otra literatura, enriquece al traductor y al lector mientras que no le quita nada del otro. Nosotros estamos felices de poder leer una parte importante de la literatura mundial y dentro de esta, la de América Latina y pensamos que nuestra literatura ofrece junto con los valores estéticos, unas enseñanzas importantes para el lector latinoamericano. 